này có thể là lý do khiến bệnh nhân giảm liều, bớt thuốc, bỏ thuốc và chỉ dùng thuốc khi quá đau qua đó giảm hiệu quả giảm đau.

\section{KẾT LUẦN}

Nghiên cứu đã ghi nhận môt lượng nhỏ bệnh nhân chưa được sử dụng thuốc giảm đau tương xứng với mức độ đau. Tỷ lê không tuân thủ sử dụng thuốc cao và những rào cản chính từ phía bệnh nhân trong quản lý đau ung thư. Các kết quả này là cơ sở cho việc xây dựng một số biện pháp, đặc biệt là các vẩn đề cần can thiệp giáo dụcbệnh nhân nhằm tăng cường hiệu quả giảm đau ung thư.

\section{TÀI LIỆU THAM KHẢO}

1. Bô Y Tế (2006), Hướng dẫn chăm sóc giảm nhe đổi với người bệnh ung thư và AIDS, Nhà xuất bản Y học, Hà Nội, pp.

2. Bandieri E., Romero M., Ripamonti C. I., Artioli F., Sichetti D., Fanizza C., Santini D., Cavanna L., Melotti B., Conte P. F., Roila F., Cascinu S., Bruera E., Tognoni G., Luppi M.
(2016), "Randomized Trial of Low-Dose Morphine Versus Weak Opioids in Moderate Cancer Pain", J Clin Oncol, 34(5), pp. 436-42.

3. National Comprehensive Cancer Network (2020), Adult cancer pain, pp.

4. Oldenmenger $W H$, Sillevis Smitt $P A$, van Dooren S, Stoter G, CC van der Rijt (2009), "A systematic review on barriers hindering adequate cancer pain management and interventions to reduce them: a critical appraisal", Eur J Cancer, 45(8), pp. 1370-1380.

5. Van den Beuken-van Everdingen $\mathbf{M H}_{\text {, }}$ Hochstenbach LM, Joosten EA, Tjan-Heijnen VC, DJ Janssen (2016), "Update on Prevalence of Pain in Patients With Cancer: Systematic Review and Meta-Analysis", J Pain Symptom Manage, 51(6), pp. 1070-1090.

6. World Health Organization (2018), WHO guidelines for the pharmacological and radiotherapeutic management of cancer pain in adults and adolescents, $\mathrm{pp}$.

7. Xu X., Luckett T., Wang A. Y., Lovell M., Phillips J. L. (2018), "Cancer pain management needs and perspectives of patients from Chinese backgrounds: a systematic review of the Chinese and English literature", Palliat Support Care, 16(6), pp. 785-799.

\title{
ĐÁNH GIÁ TRÌNH TRANG NẢY CHỒI U TRONG UNG THƯ VÚ THỂ ỐNG XÂM NHẬP BẰNG GIẢI PHẪU BỆNH KỸ THUÂTT Số
}

\section{TÓM TẮT}

Trong ung thư biểu mô (UTBM) tuyến vú xâm nhập, NCU độ cao tương quan với kích thước u lớn, xâm nhập mạch, di căn hạch và giảm tỷ lệ sống 5 năm của bệnh nhẩn ung thư vú. Mục tiêu: (1) Xác định tỷ lệ các mức độ nảy chồi u trong ung thư biểu mô tuyến vú thể ống xâm nhâp. (2) Nhân xét môt số mối liên quân giữa các mức nảy chồi u với các đặc điểm giải phẫu bênh. Đối tượng và phương pháp nghiên cứu: Mẫu mô u của 232 bệnh nhân ung thư vú thể ống xâm nhâp được được số hóa tiêu bản thông thường để xác định NCU theo ITBCC 2016 bằng phần mềm kính hiển vi ảo trên máy tính và đánh giá mối liên quan với một số đặc điểm GPB. Kết quả nghiên cứu: Tỷ lệ NCU đô cao trong nhóm ĐMH III là 35,1\%, cao hơn so với tỷ lệ NCU độ cao trong nhóm ĐMH I-II là 20,3\%. Tương tự, ở NC்U đô cao, UTV có di căn hạch là $41,8 \%$, cao hơn 2 lần so nhóm không có di cắn $(20,3 \%)$. Tỷ lệ NCU đô cao trong nhóm u có kích thước pT3 là 63,6\%, cao hơn tỷ lệ NCU độ cao trong nhóm u có kích thước pT1 \& pT2 là 25,8\%. Trong

\section{*Bệnh viện $K$}

Chịu trách nhiẹm chính: Nguyễn Văn Chủ

Email: chunv.nch@gmail.com

Ngày nhận bài:3.8.2021

Ngày phản biện khoa học: 1.10 .2021

Ngày duyệt bài: 12.10.2021

\author{
Nguyễn Văn Chủ*, Lê Thị Uyên**
}

nhóm có xâm nhập mạch bạch huyết, NCU độ cao là $35,6 \%$, cao hơn 1,5 lần so với nhóm không xâm nhâp mạch bạch huyết là 22,5\% ( $p<0,05)$. Kết luận: Có sự tương quan chặt chẽ giữa NCU độ cao với u kích thước lớn, di căn hạch nách, ĐMH cao, xâm nhập mạch bạch huyết.

Tư khóa: Nảy chồi u, Mô bệnh học, Ung thư vú, Giải phẫu bệnh số.

\section{SUMMARY \\ ASSESSMENT OF TUMOR BUDDING IN INVASIVE DUCTAL BREAST CARCINOMA BY DIGITAL PATHOLOGY}

In invasive breast carcinoma, tumor budding, highgrade correlates with tumor size, lymphavascular invasion, lymph node metastasis, and reduced 5-year survival of breast cancer patients. Purpose: (1) Determination of the tumor budding rates in invasive ductal breast carcinoma. (2) Commenting on some relationships between tumor budding levels and pathological characteristics. Methods: Tumor samples of 232 patients with invasive ductal breast cancer were digitized the conventional slides to identify Bds according to ITBCC 2016 by computer virtual microscope software and evaluated the relationship with some pathological features. Results: The rate of high-grade $\mathrm{Bd}$ of the grade III was $35.1 \%$, higher than high-grade Bd of the grade I and II of $20.3 \%$. Similarly, in high-grade Bd, breast cancer with lymph node metastasis was $41.8 \%$, twices higher than the group without metastasis (20.3\%). The rate of high- 
grade Bd in the pT3 tumors was $63.6 \%$, higher than the pT1 \& pT2 (25.8\%). In the tumors with lymphavascular invasion, high-grade Bd was $35.6 \%$, which was 1.5 times higher than that in the group without lymphatic infiltration of $22.5 \% \quad(p<0.05)$. Conclusion: There is a strong correlation between high-grade $\mathrm{Bd}$ and large tumor, axillary lymph node metastasis, high grade, and lymphavascular invasion.

Key words: Tumor budding, Histopathology, Breast cancer, Digital pathology.

\section{I. ĐẶT VẤN ĐỀ}

Các yếu tố tiên lượng trong ung thư vú đóng vai trò đặc biệt quan trọng giúp cung cấp các thông tin cho điều trị và tiên lượng bệnh. Các yếu tố tiên lượng kinh điển như kích thước $u$, typ mô bệnh học (MBH), độ mô học (ĐMH), chỉ số tiên lượng Nottingham (NPI), giai đoạn u, tình trạng hạch và xâm nhập mạch. Gần đây, một số yểu tố mới như nảy chồi u (NCU) được đề cập. NCU là sự xuất hiện các tế bào u độc lập hoặc nhóm nhỏ ít hơn hoă̆c bằng 4 tế bào u. Sư NCU nằm rải rác trong mô đệm ở bờ xâm nhập của khối $u$, có xu hướng mất kết dính và tách ra thành các tế bào đơn lẻ [1].

Thuật ngữ nảy chồi u đã được nghiên cứu trên nhiều loại ung thư đặc không chỉ ung thư vú, như: ung thư đại trực tràng, ung thư dạ dày, ung thư tụy, ung thư vùng đầu cổ, ung thư phối [1]. Trong ung thư biểu mô (UTBM) tuyến vú xâm nhập, NCU độ cao tương quan với kích thước u lớn, xâm nhập mạch máu - bạch huyết và di căn hạch [2]. NCU độ cao với giảm tỳ lệ sống 5 năm của bệnh nhân ung thư vú [3]. Việc số hóa các tiêu bản thông thường đã và đang là một xu hướng rất hiện đại trên thế giới, đem lại nhiều lợi ích to lớn trong thực hành. Ở Việt Nam, NCU đã được nghiên cứu ở một số khối u đặc như ung thư đại trực tràng, da dày, thực quản..., tuy nhiên chưa có công trình nào nghiên cứu trong ung thư vú thể ống xâm nhập (OXN). Vì vậy, chúng tôi chọn đề tài này với mục tiêu:

- Xác định tỷ lệ các mức độ nảy chồi u trong ung thư biểu mô tuyến vú thể ống xâm nhập.

- Nhận xét mốt số mối liên quan giữa các mức nảy chồi u với các đặc điểm giải phấu bệnh.

\section{II. ĐỐI TƯỢNG VÀ PHƯƠNG PHÁP NGHIÊN CỨU}

Đối tượng nghiên cứu: gồm 232 bệnh nhân ung thư biểu mô tuyến vú thể OXN được phẫu thuật điều trị tại bệnh viện K.

Tiêu chuẩn lựa chọn đối tượng

- Có ghi nhận đầy đủ các dữ kiện: họ tên, tuổi, ngày vào viện, vị trí khối u, chẩn đoán lâm sàng và giai đoạn lâm sàng.

- Được phẫu thuật cắt tuyến vú.
- Chẩn đoán xác định bằng mô bệnh học là UTBM thể OXN.

- Có tiêu bản nhuộm H\&E, nhuộm ER, PR, Her2/neu và Ki67.

- Khối u vú nguyên phát và chưa được điều trị hóa chất trước mổ cắt u.

- Ung thư vú ở giai đoạn I-III.

Tiêu chuẩn loại trừ: Các trường hợp sau sẽ bị loại khỏi nghiên cứu:

- Không đáp ứng được các tiêu chuẩn lựa chọn trên.

- Ung thư biểu mô tuyến vú tại chỗ.

- Ung thư vú tái phát hoặc cơ quan khác di căn tới vú.

- Ung thư vú ở nam giới.

\section{Phương pháp nghiên cứu}

- Thiết kế nghiên cứu: là nghiên cứu mô tả cắt ngang.

- Mẫu nghiên cứu: Mẫu không xác suất, loại mẫu có chủ đích.

- Nội dung nghiên cứu/ Các biến số và chỉ số trong nghiên cứu:

+ Đặc điểm chung

- Kích thước u: $\leq 2 \mathrm{~cm},>2-5 \mathrm{~cm}$ và $>5 \mathrm{~cm}$

- Vị trí u: Vú phải, vú trái, hai bên

- Giai đoạn bệnh: theo AJCC 8

- Hoại tử u: có/không

- Tỉ lệ các typ mô bệnh học: theo phân loại WHO 2019

- Tình trạng bộc lộ ER, PR, Heu-2, Ki67: dương tính/âmm tính

- Tình trạng di căn hạch nách: 0, 1-3, >3 hạch

- Xâm nhập mạch: có/không

+ Mục tiêu 1

- Độ NCU: chia làm 3 độ I, II và III theo ITBCC 2016

\begin{tabular}{|c|c|}
\hline Độ nảy chồi u & Đặc điếm \\
\hline III & $\geq 10$ chồi \\
\hline II & $5-9$ chồi \\
\hline I & $0-4 \quad$ chồi \\
\hline
\end{tabular}

- Độ I, II và III được nhóm thành độ thấp (I và II) và độ cao (III).

+ Mục tiêu 2: Đối chiếu độ NCU (thấp-vừa \& cao) với kích thước u và các đặc điểm $\mathrm{MBH}$ : typ $\mathrm{MBH}, \mathrm{DMH}$ (I và II, III), giai đoạn $u$, hoại tử u, di căn hạch (có/không), xâm nhập mạch (có/không), ER (dương tính/âm tính), PR (dương tính/âm tính), Ki67 (dương tính thấp và cao), Her2/neu (dương tính/âm tính).

- Quy trình nghiên cứu

+ Đặc điểm chung: lập danh sách bệnh nhân và thu thập thông tin từ bệnh án.

+ Đặc điểm mô bệnh học và đặc điểm nảy chồi u 
- Đặc điểm $\mathrm{MBH}$ : thu thập các tiêu bản nhuộm $\mathrm{HE}$, đọc và phân tích kết quả trên kính hiển vi quang học. Trường hợp tiêu bản không đảm bảo chất lượng sẽ làm tiểu bản mới từ khối nến còn lại của bệnh nhân.

- Số hóa tiêu bản HE và đánh giá đặc điểm nảy chồi u: Các tiêu bản HE được quét bằng máy Scan tiêu bản Leica Aperio AT2 với các độ phóng đại khác nhau để số hóa. Các tiêu bản số này được đọc bằng phần mềm trên máy tính ở vật kính ảo phóng đại 200 lần và phân độ nảy chồi u theo quy trình của ITBCC 2016.

- Bộ công cụ nghiên cứu và kĩ thuật thu thập số liệu: Hệ thống máy Scan tiêu bản Leica Aperio AT2 và phiếu nghiên cứu.

Phân tích và xử lý số liệu: Xử lý số liệu bằng phần mềm SPSS 16. Áp dụng test $X 2$ để so sánh hai hoặc nhiều tỷ lệ, tính giá trị p. Các phép so sánh có $\mathrm{p}<0,05$ được coi là có ý nghĩa thống kê.

\section{KẾT QUẢ NGHIÊN CỨU}

Bảng 1. Tình trạng nảy chồi u

\begin{tabular}{|c|c|c|c|c|c|}
\hline \multicolumn{2}{|c|}{ Độ NCU } & \multicolumn{2}{|c|}{$\mathbf{N}$} & \multicolumn{2}{|c|}{$\%$} \\
\hline $\begin{array}{c}\text { I } \\
\text { II }\end{array}$ & Thấp & $\begin{array}{c}103 \\
65\end{array}$ & 168 & $\begin{array}{l}44,4 \\
28,0\end{array}$ & 72,4 \\
\hline III & Cao & \multirow{2}{*}{\multicolumn{2}{|c|}{$\begin{array}{c}64 \\
232\end{array}$}} & \multirow{2}{*}{\multicolumn{2}{|c|}{$\begin{array}{c}27,6 \\
\mathbf{1 0 0 , 0}\end{array}$}} \\
\hline & & & & & \\
\hline
\end{tabular}

Nhân xét: Tỷ lệ NCU độ thấp là 72,4\%, trong đó độ I là 44,4\% với 103 trường hợp, chiếm tỉ lệ cao nhất trong mẫu nghiên cứu và NCU độ II với 65 trưởng hợp, chiếm 28,0\%. Tỷ lệ NCU độ III (độ cao) là $27,6 \%$ với 64 trường hơp.

Bảng 2. Đối chiếu đặc điểm NCU với một số đặc điểm giải phẫu bệnh

\begin{tabular}{|c|c|c|c|c|c|c|}
\hline \multirow{2}{*}{\multicolumn{2}{|c|}{ Độ NCU }} & \multirow{2}{*}{\multicolumn{2}{|c|}{ Độ thấp }} & & & \\
\hline & & & & \multicolumn{2}{|c|}{ Đố cao } & $\mathbf{p}$ \\
\hline \multirow[b]{2}{*}{ ĐMH } & I-II & 94 & 79,7 & 40 & 35,1 & \multirow{2}{*}{0,012} \\
\hline & III & 74 & 64,9 & 24 & 20,3 & \\
\hline \multirow{2}{*}{$\begin{array}{l}\text { Di căn } \\
\text { hạch }\end{array}$} & 0 & 122 & 79,7 & 31 & 20,3 & \multirow{2}{*}{0,001} \\
\hline & $1-3$ & 46 & 58,2 & 33 & 41,8 & \\
\hline \multirow{2}{*}{ pT } & T1-2 & 164 & 74,2 & 57 & 25,8 & \multirow{2}{*}{0,006} \\
\hline & T3 & 4 & 36,4 & 7 & 63,6 & \\
\hline \multirow{2}{*}{ XN mạch } & Không & 110 & 77,5 & 32 & 22,5 & \multirow{2}{*}{0,031} \\
\hline & Có & 58 & 64,4 & 32 & 35,6 & \\
\hline \multirow{2}{*}{ Hoại tử } & Không & 136 & 72,7 & 51 & 27,3 & \multirow{2}{*}{0,828} \\
\hline & Có & 32 & 71,1 & 13 & 28,9 & \\
\hline
\end{tabular}

Nhận xét: Tỷ lệ NCU độ cao trong nhóm ĐMH III là $35,1 \%$, cao hơn so với tỷ lệ NCU độ cao trong nhóm ĐMH I-II là 20,3\%. Tương tự, ở NCU độ cao, UTV có di căn hạch là 41,8\%, cao hớn 2 lần so nhóm không có di căn (20,3\%). Tý lệ NCU độ cao trong nhóm u có kích thước pT3 là $63,6 \%$, cao hơn tỷ lệ NCU độ cao trong nhóm u có kích thước pT1 \& pT2 là 25,8\%. Trong nhóm có xâm nhập mạch bach huyết NCUU độ cao là 35,6\%, cao hơn 1,5 lần so với nhóm không xâm nhập mạch bạch huyết là $22,5 \%$. Tỷ lệ NCU độ cao ở nhóm có hoại tử u và không hoại tử của tỷ lệ gần tương tự nhau (lần lượt là 28,9 và $27,3 \%$ ).

Bảng 3. Nảy chối u và sự bộc lộ các dấu ấn HMMD

\begin{tabular}{|c|c|c|c|c|c|c|}
\hline \multirow{2}{*}{\multicolumn{2}{|c|}{ Độ NCU }} & \multicolumn{2}{|c|}{ Đô thấp } & \multicolumn{2}{|c|}{ Đố cao } & \multirow{2}{*}{$\mathbf{p}$} \\
\hline & & $\mathbf{N}$ & $\%$ & $\mathbf{n}$ & $\%$ & \\
\hline \multirow[b]{2}{*}{ ER } & $(-)$ & 69 & 67,0 & 34 & 33,0 & \multirow{2}{*}{0,099} \\
\hline & $(+)$ & 99 & 76,7 & 30 & 23,3 & \\
\hline \multirow{2}{*}{ PR } & $(-)$ & 75 & 67,0 & 93 & 77,5 & \multirow{2}{*}{0,073} \\
\hline & $(+)$ & 37 & 33,0 & 27 & 22,5 & \\
\hline \multirow{2}{*}{ HER2 } & $(-)$ & 93 & 76,2 & 29 & 23,8 & \multirow{2}{*}{0,171} \\
\hline & $(+)$ & 75 & 68,2 & 35 & 31,8 & \\
\hline \multirow{2}{*}{ Ki67 } & Thấp & 87 & 75,0 & 29 & 25,0 & \multirow{2}{*}{0,378} \\
\hline & Cao & 81 & 69,8 & 35 & 30,2 & \\
\hline
\end{tabular}

Nhận xét: Tỷ lệ NCU độ cao ở nhóm ER(-) là $33,0 \%$ cao hơn nhóm $\mathrm{ER}(+)$ là $23,3 \%$. Tương tự, trong UTV PR(-), NCU đô cao là $33,0 \%$, cao hơn nhóm có $\mathrm{PR}(+)$ là $22,5 \%$. Trái lại, NCU độ cao trong nhóm bộc lộ HER2(+) là 31,8\%, cao hơn với tỷ lệ NCU độ cao UTV HER2(-) là 23,8\%. Tỷ lê NCU độ cao trong nhóm có chỉ số Ki67 cao là $30,2 \%$, cao hơn với tỷ lệ NCU độ cao trong 
nhóm có chỉ số Ki67 thấp là 25,0\%.

\section{BÀN LUẬN}

Giải phẫu bênh kỹ thuật số phát triển mạnh trong một vài năm gần đây. Việc số hóa tiêu bản thông thường đã đem lại nhiều lợi ích to lớn cho việc chẩn đoán, đào tạo, nghiên cứu khoa học và hội chẩn. Chúng tôi đánh giá NCU trên tiêu bản nhuộm HE đã được số hóa, sử dụng phương pháp đếm NCU ở vùng "hotspot" của ITBCC 2016 [1]. Số lượng NCU thấp nhất là 0 chồi u/0,785 mm²; cao nhất là 33 chồi u/ $0,785 \mathrm{~mm}^{2}$; trung bình là 7 chồi $u / 0,785 \mathrm{~mm}^{2}$. NCU độ cao chiếm tỷ lệ 27,6\% với 103 trường hợp. NCU độ trung bình và độ thấp chiếm lần lượt $28 \%$ và $44,4 \%$. NCU sẽ được đếm với độ chính xác tốt hơn nếu được đếm trên 10 vi trường. Các nghiên cứu sử dụng các điểm cắt khác nhau để phân độ các mức NCU. Nghiên cứu của chúng tôi chia làm ba độ: độ thấp (0-4 NCU), độ trung bình (5-9 $\mathrm{NCU})$ và độ cao ( $\geq 10 \mathrm{NCU}$ ) tương tự cách phân độ trong nghiên cứu của Sun và cS [4] cho kết quả NCU hai nghiên cứu tương tự nhau. Tuy nhiên cũng có sự khác biệt về tỷ lệ NCU khá nhiều giữa các nghiên cứu có thể do sử dụng các phương pháp đếm khác nhau. Trong đó tỷ lệ NCU độ cao chiếm tỷ lệ cao nhất trong hai nghiên cứu của Salhia và $\mathrm{Cs}$, Masilamani và $\mathrm{CS}$ lần lượt là $88,5 \%$ và $80,4 \%[5,6]$.

Trong nghiên cứu của chúng tôi, tỷ lệ NCU độ cao trong nhóm Độ III là 35,1\% (40/114 trường hợp), cao hơn so với tỷ lệ NCU độ cao trong nhóm ĐMH I-II là 20,3\% (24/118 trường hợp). Sự khác biệt này có ý nghĩa thống kê với $\mathrm{p}=$ $0,012(<0,005)$. Kết quả của chúng tôi tương đồng với tác giả Sriwidyani và cs $(p=0,03)$ [7]. Nghiên cứu của Renuka và cs cho kết quả NCU không có tương quan với ĐMH nhưng có mối liên quan với độ mô học với $p=0,048$ [8].

Nghiên cứu của chúng tôi nhận thấy có sự khác biệt giữa phân độ NCU và số lượng hạch di căn hạch: u di căn nhiêu hạch có tỷ lệ NCU độ cao cao hơn so với nhóm di căn ít hạch và sự khác biệt này có ý nghĩa thống kê với $\mathrm{p}<0,001$. Kết quả của chúng tôi tương tự với một số nghiên cứu nước ngoài, nghiên cứu của Gujam và cs [3] cho kết quả tỷ lệ NCU độ cao trong nhóm có di căn hạch là $41,5 \%$ cao hơn so với tỳ lệ NCU độ cao trong nhóm không di căn hạch (30\%), mối liên quan có ý nghĩa thống kê với $p$ $=0,009$. Nghiên cứu của Masilamani và cs [6] trên 107 bệnh nhân thây rằng trong số 43 trường hợp di căn hạch thì có tới 90,7\% NCU độ cao; trong khi chỉ 73,4\% NCU độ cao xảy ra trên những bệnh nhân không di căn hạch. Kết quả nghiên cứu cho thấy có mối liên quan đáng kể giữa NCU độ cao và tình trạng di căn hạch với $p$ $<0,05$. Kết quả nghiên cứu của chúng tôi ủng hộ các nghiên cứu trước đây cho rằng NCU là yểu tố mô bệnh học có khả năng tiên lượng tình trạng di căn hạch trong ung thư vú mặc dù sử dụng các phương pháp đánh giá khác nhau.

Trong nghiên cứu của chúng tôi cho thấy $\mathrm{NCU}$ có mối tương quan với kích thước u ( $p=$ 0,006 ). Kết quả của chúng tôi tương tự nghiên cứu của Liang và cs [2]. Tương tự, nghiên cứu của các tác giả Sriwidyani và cs [7], Agarwal và Cs [9], Kumarguru và cs [10] cũng cho thây NCU có mối liên quan với kích thước u trong UTBM xâm nhập.

Chúng tôi nhận thấy tỷ lệ NCU độ cao trong nhóm có xâm nhập mạch bạch huyết là $35,6 \%$, cao hơn 1,5 lần so với tỷ lệ NCU độ cao trong nhóm không xâm nhập mạch bạch huyết là $22,5 \%$. Sự khác biệt này có ý nghĩa thống kê với $p=0,031$. Ngược lại trong một nghiên cứu cho kết quả không có sự tương quan có ý nghĩa giữa các mức độ NCU với tình trạng xâm nhập mạch bạch huyết $(p=0,553)$. Mặc dù không có ý nghĩa thống kê nhưng tỷ lệ NCU dương tính trong nhóm xâm nhập mạch $80 \%$ cao hơn trong nhóm không có xâm nhập mạch $(73,1 \%)$. Một phân tích gộp của cũng đã cho thấy có mối tương quan giữa NCU với tình trạng xâm nhập mạch bạch huyết. Tỷ lệ NCU trong nhóm có xâm nhập mạch bạch huyết cao hơn trong nhóm khồng có xâm nhập mạch. Điều này phù hợp với quá trình EMT trong sự tiến triển và di căn của ung thư. Các tế bào chồi u là các tế bào đang trải qua EMT, diễn ra các thay đổi sinh học cho phép xâm nhập mạch bạch huyết và là mầm mống của di cắn xa.

Nghiên cứu của chúng tôi cho thấy không có mối liên quan giữa NCU và tình trạng hoại tử u với $p=0,828$. Kết quả này tương tự nghiển cứu của Gujam và $c s(p=0,107)[3]$, Agarwal và $c s$ $(p=0,283)[9]$. Theo của Kumarguru và cs, tỷ lệ NCU độ cao có mối liên quan với các trường hợp có hoại tử u.

Khi đánh giá sự bộc lộ ER, kết quả nghiên cứu của chúng tôi tượng tự các nghiên cứu của Liang và cs [2], Sriwidyani và cs [7], Masilamani và cs [6], Agarwal và cs [9], Renuka và cs [6]. Tuy nhiên, nghiên cứu của Gujam và cs [3], Salhia và cs [5] cho thấy mối tương quan giữa NCU với sự bộc lộ ER. Tỷ lệ NCU độ cao trong nhóm bộc lộ ER dương tính cao hơn tỷ lệ NCU độ 
cao trong nhóm ER âm tính. Theo kết quả nghiên cứu Gujam và cS, cho thấy NCU độ cao có liên quan đáng kể với các khối u ER dương tính. Gần đây, đã có báo cáo rằng estrogen có liên quan đến quá trình EMT [3], liên quan đến sự phá vỡ mối nối giữa các tế bào biểu mô và tăng khả năng vận động của các tế bào. Do đó, các khối u $E R(+)$ thì có thể trải qua mức độ EMT cao hơn và tiêm năng di căn nhiều hơn. Theo Sun và cs (2014) [6], estrogen có liên quan đến EMT trong các dòng tế bào UTV có đặc tính tế bào gốc (CSC), CSC đóng vai trò quan trọng trong sự phát triển, xâm lấn, di căn khối u, chống lại các tác nhân gây độc tế bào. Kết quả nghiên cứu của Sun và cs chỉ ra rằng hoạt động thông qua Gli1 (kích hoạt phiên mã Gli1) để thúc đẩy sự phát triển của CSC và ETM trong các tế bào UTV có ER dương tính.

Đối với sự bộc lộ $P R$, các nghiên cứu của Liang và cs [2], Gujam và cs [3], Sriwidyani và cs [7], Masilamani và cs [6], Agarwal và cs [9] đều cho kết quả không có mối tương quan giữa NCU và sự bộc lộ PR. Một số tác giả khi so sánh sự bộc lộ HMMD giữa các tế bào chồi u và khối u chính chỉ quan sát thấy sự khác biệt về tình trang bộc PR. Các thí nghiệm trên các dòng tế bào ung thư vú đã chứng minh rằng gắn với $P R$ có thể dẫn đến ức chế các protein liên quan đến EMT và $P R$ âm tính là yếu tố độc lập làm giảm tỷ lệ sống sót.

Trong sự bộc lộ HER2, nghiên cứu của Liang và cs [2], Gujam và cs [3], Salhia và cs [5], Sriwidyani và cs [7], Agarwal và cs [9] cho kết quả không có mối tương quan giữa NCU và sự bộc lộ HER2. Ngược lại, nghiên cứu của Masilamani và cs [6] chỉ ra rằng NCU độ cao có liên quan đến các khối u có HER2 dương tính.

Đánh giá sư bộc lộ Ki67, các nghiên cứu của Gujam và cs [3], Masilamani và cs [6] cho kết quả giống với nghiên cứu của chúng tôi. Nghiên cứu của Salhia và cs [5], Sriwidyani và cs [7] chỉ ra mối tương quan giữa NCU và sự bộc lộ Ki67, trong nghiên cứu Salhia và cs [5] chỉ ra rằng tý lệ NCU độ cao liên quan đến u có chỉ số Ki67 thấp ( $\leq 15 \%)$. Mức độ bộc lộ Ki67 càng cao thì tiên lượng càng xấu, tuy nhiên các nghiên cứu về quá trình EMT cho thấy các tế bào của chồi u cũng biểu hiện mức độ thấp của chỉ số Ki67 và không có dấu hiệu tăng sinh. Nghiên cứu của một số tác giả trền ung thư đại trực tràng cũng cho kết quả tương tự Ki67 không bộc lộ trong hầu hết các tế bào của chồi u.

\section{KẾT LUÂN}

Qua nghiên cứu đánh giá NCU của 232 bệnh nhân ung thư biểu mô tuyến vú thể ống xâm nhập chúng tôi rút ra một số nhận xét sau:

- NCU độ thấp là $72,4 \%$, trong đó độ I chiếm tỉ lệ cao nhất là $44,4 \%$ và độ II là $28,0 \%$. Tỷ lệ NCU độ cao (độ III) chiếm 27,6\%.

- Có sự tương quan chặt chẽ giữa NCU độ cao với u kích thước lớn, di căn hạch nách, ĐMH cao, xâm nhập mạch bạch huyết $(p<0,05)$. Tuy nhiên, chưa thây sự tương quan giữa mức độ NCU với tình trạng hoại tử u và đặc điểm HMMD.

\section{TÀI LIỆ THAM KHẢO}

1. Lugli A, Kirsch $R$, Ajioka $Y$, et al. Recommendations for reporting tumor budding in colorectal cancer based on the International Tumor Budding Consensus Conference (ITBCC) 2016. Modern pathology : an official journal of the United States and Canadian Academy of Pathology, Inc. Sep 2017;30(9):1299-1311.

2. Liang F, Cao W, Wang Y, Li L, Zhang G, Wang $\mathbf{Z}$. The prognostic value of tumor budding in invasive breast cancer. Pathology, research and practice. May 2013;209(5):269-75.

3. Gujam FJ, McMillan DC, Mohammed ZM, Edwards J, Going JJ. The relationship between tumour budding, the tumour microenvironment and survival in patients with invasive ductal breast cancer. British journal of cancer. Sep 29 2015;113(7):1066-74. doi:10.1038/bjc.2015.287

4. Sun $\mathbf{Y}$, Liang $\mathbf{F}$, Cao $\mathbf{W}$, et al. Prognostic value of poorly differentiated clusters in invasive breast cancer. World journal of surgical oncology. Oct 12 2014;12:310.

5. Salhia B, Trippel M, Pfaltz $K$, et al. High tumor budding stratifies breast cancer with metastatic properties. Breast cancer research and treatment. Apr 2015;150(2):363-71.

6. Masilamani DS, P DK. Evaluation of clinicopathologic significance of tumor budding in breast carcinoma. International Journal of Clinical and Diagnostic Pathology. 2019;2(1):171-173.

7. Sriwidyani NP, Manuaba IBTW, Alit-Artha IG, Mantik-Astawa IN. Tumor Budding in Breast Carcinoma: Relation to E-Cadherin, MMP-9 Expression, and Metastasis Risk. Tumor budding, E-cadherin, MMP-9, metastasis, breast carcinoma. 2016. 2016-10-22 2016;5(3):5.

8. Renuka IV, Madhavi $K$, Premalatha $P$, Krishnamacharyulu P, Vaishnavi R. Tumor budding in invasive carcinoma of breast of No Special Type (NST): Value as a prognostic factor. IP J Diagn Pathol Oncol 2019;4(2):15-129.

9. Agarwal $\mathbf{R}$, Khurana $\mathbf{N}$, Singh $T$, Agarwal PN. Tumor budding in infiltrating breast carcinoma: Correlation with known clinicopathological parameters and hormone receptor status. Indian journal of pathology \& microbiology. Apr-Jun 2019;62(2):222-225. 